\title{
Calcineurin-nuclear factor for activated $T$ cells (NFAT) signaling in pathophysiology of wound healing
}

\author{
Takahiro Manabe, Heamin Park and Takashi Minami ${ }^{*}$
}

\begin{abstract}
Wound healing occurred with serial coordinated processes via coagulation-fibrinolysis, inflammation following to immune-activation, angiogenesis, granulation, and the final re-epithelization. Since the dermis forms critical physical and biological barriers, the repair system should be rapidly and accurately functioned to keep homeostasis in our body. The wound healing is impaired or dysregulated via an inappropriate microenvironment, which is easy to lead to several diseases, including fibrosis in multiple organs and psoriasis. Such a disease led to the dysregulation of several types of cells: immune cells, fibroblasts, mural cells, and endothelial cells. Moreover, recent progress in medical studies uncovers the significant concept. The calcium signaling, typically the following calcineurin-NFAT signaling, essentially regulates not only immune cell activations, but also various healing steps via coagulation, inflammation, and angiogenesis. In this review, we summarize the role of the NFAT activation pathway in wound healing and discuss its overall impact on future therapeutic ways.
\end{abstract}

Keywords: Wound healing, NFAT, Coagulation, Angiogenesis, Inflammation

\section{Background}

Wound healing occurred with a coordinative process of three phases: inflammation, proliferation, and remodeling. When tissues are injured, they initially occur clot formation to stop the bleeding following inflammation. In this phase, hemostatic balance and immune control are critical for precise wound healing. Macrophage and neutrophils migrate to the wound site to perform infection control, and platelets release several growth factors involving vascular endothelial growth factor (VEGF), fibroblast growth factor (FGF), and platelet-derived growth factor (PDGF) [1]. These factors can lead to the next proliferation phase causing re-epithelialization, granulation, and angiogenesis. Re-epithelialization starts within a few hours after injury [2]. Clots and damaged stroma are removed from the skin, mediated by the proliferation and migrations of epithelial cells and

\footnotetext{
* Correspondence: t-minami@kumamoto-u.ac.jp

Division of Molecular and Vascular Biology, IRDA, Kumamoto University, 2-2-1 Honjyo Chuo-ku, Kumamoto 860-0811, Japan
}

keratinocytes. In these cells, tonofilament and actin filament are reorganized. These disrupt hemidesmosome links between the epidermis and the basement membrane, which allows dynamic movement of epidermal cells. Epithelial cells also release growth factors, including epithelial growth factor (EGF), which lead to reepithelization and granulations [3]. The final phase, remodeling, occurred via the combinations among at least mesenchymal cells, vessel-forming endothelial cells and pericytes, and fibroblasts. These cells activate in the presence of several cytokines that reveal higher migration capacities and extracellular matrix production in granulation tissue [4].

Angiogenesis plays a key role in wound healing. It is needed to transport oxygen and nutrition, vital for cells, to the wound site. By migration and proliferation of these cells, a wound in tissue is filled. After the proper angiogenesis process, granulation tissue is replaced by an acellular scar due to cell apoptosis. But at last, no longer needed abundant angiogenic blood vessels are

(c) The Author(s). 2021 Open Access This article is licensed under a Creative Commons Attribution 4.0 International License, which permits use, sharing, adaptation, distribution and reproduction in any medium or format, as long as you give appropriate credit to the original author(s) and the source, provide a link to the Creative Commons licence, and indicate if changes were made. The images or other third party material in this article are included in the article's Creative Commons licence, unless indicated otherwise in a credit line to the material. If material is not included in the article's Creative Commons licence and your intended use is not permitted by statutory regulation or exceeds the permitted use, you will need to obtain permission directly from the copyright holder. To view a copy of this licence, visit http://creativecommons.org/licenses/by/4.0/. 
regressed [5]. These angiogenesis and tissue-granulation processes overlap in time, and the coordination of each step is essential for wound healing.

Interestingly, calcium homeostasis is related to wound healing status. For example, calcitonin treatment upregulates calcium levels in wound sites. The upregulated calcium leads to enhanced wound healing in rabbits [6] and rats [7]. Low-calcium diets resulted in delayed wound healing in vitamin D receptor knockout mice [8]. Moreover, calcium influx stimulates through phospholipase $\mathrm{C}$ pathways that lead several downstream signal axis, including protein kinase $\mathrm{C}$ and calmodulin. Calcineurin activation also occurred following NFAT nuclear localization in many cell types. NFAT is a famous immune- or inflammatory regulated transcription factor that obtains a family with several types of isoforms: NFAT1 to 4. Calcineurin-NFAT inhibitor, cyclosporine A (CsA), is the most famous immunosuppressive drug after organ transplantations. Moreover, it is known that downregulation of calcineurin attenuates neural inflammation via tau hyperphosphorylation in neuronal cells [9]. In this review, we are going to focus on the NFAT signaling in multiple wound healing steps as shown below related to several pathologies.

\section{Main text \\ NFAT signaling in coagulations}

The coagulation process consists of platelet adhesion, secretion, and aggregation. Wound-initiated coagulation, extrinsic pathway, is started by tissue factor (TF) expression on the perivascular tissue surfaces. TF is a transmembrane glycoprotein that binds to factor VII following the proteolytic activation (FVIIa). Such TFFVIIa complex activates the downstream coagulation pathways and finally leads to thrombin burst [10]. Since TF promoter has a functional NFAT-binding site, TF expression is induced by VEGF [11] and oxidized phospholipids [12] via calcineurin-NFAT signaling. However, NFAT overactivation may destabilize the coagulation balance. NFAT can also induce cyclooxygenase (COX) 2 . It has been reported that $\operatorname{cox} 2$ and its inhibition cause complex outcomes, blocking or enhancing clot formation (Fig. 1). Moreover, clinical use of cyclosporine (CsA) was suggested to be associated with an increased risk of thromboembolic complications. Platelets treated with CsA in vitro induced procoagulant activity. However, compared to CsA, tacrolimus (also known as FK506) significantly decreased the propensity to form thrombus of cardiac allograft vasculopathy. Nevertheless, these immunosuppressive drugs are not entirely dependent on NFAT inhibition. Thus, the molecular mechanisms underlying these complex effects remain unresolved.

\section{NFAT signaling in inflammations}

Inflammation occurs as a necessary process for wound healing. In this phase, innate immune cells; macrophages and mast cells, predominantly activate to control infection and enhance many cell proliferation. Macrophages infiltrate to the wounded area for phagocytosing specific proteins of extracellular matrix from foreign particles or bacteria via binding to macrophage's integrin receptor. In such innate immunity, NFAT signaling is known to have critical roles. For example, NFAT-bound enhancers on the IL-3 gene locus promote macrophage differentiation from stem cells [13], which proceed the inflammation via releasing TNF- $\alpha$. Macrophages are known to secrete interleukin (IL)-2 or 6, which introduces cell proliferation by themselves. Especially macrophages in the healing process, phenotype switching from classically inflamed (M1) to "wound healing macrophage (M2-like)" occurred [1]. In the early wounds, stimulation of Tolllike receptors (TLR) 1, 2, and 4 by lipopolysaccharide (LPS) induces macrophage activation under the nuclear localization of NFAT3 and 4 (Fig. 1). As the wound healing progresses, macrophages transform into wound healing macrophages by a complex of factors, IL-10, glucocorticoids, prostaglandins, metabolites, and the process of efferocytosis [14].

It has been reported that mast cells are required for proper wound healing. Mast cells accumulate within 24 $\mathrm{h}$ from the injury and release cytokines, VEGF and histamine, which are necessary to proliferate for angiogenic endothelial cells and mast cells by themselves, respectively [15]. In activated mast cells, the Hif- $1 \alpha$ gene is upregulated via NFAT binding to the promoter region, which can induce the downstream VEGF expression via phosphatidylinositol 3-kinase-dependent manner.

\section{NFAT signaling in re-epithelialization and granulations}

To reduce the infection risks of the wound area, the socalled re-epithelialization, instant barrier is formed within a few hours by migration and proliferation [16]. In keratinocytes, NFAT activation is reported to accelerate $\mathrm{T}$-typed plastin (T-plastin) synthesis and promote migration (Fig. 1). T-PLASMIN is an ACTIN binding protein belonging to the fimbrin family and helps the assembly and stabilization of the actin fiber network [17]. In contrast, NFAT inhibitor treatment decreases the migration of keratinocytes [18]. It suggests the direct correlation between CsA treatment and the dysregulation of wound healing in patients [19].

Although re-epithelialization is completed, granulation is still ongoing under the epidermis. Granulation tissue appears within 3-5 days after the injury [20]. In this phase, due to the maximal activation of mesenchymal stromal cells and fibroblasts, the migration capacities and following the ECM production are increased [5]. 


\section{Coagulation}

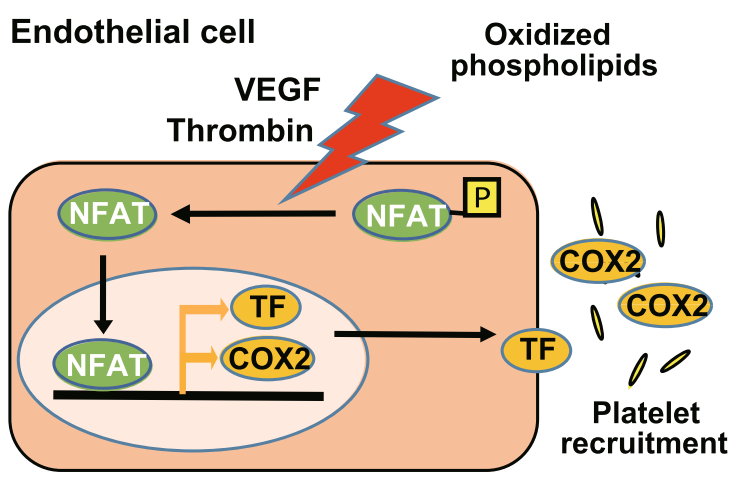

\section{Re-epithelialization \& Granulation}

\section{Keratinocyte}
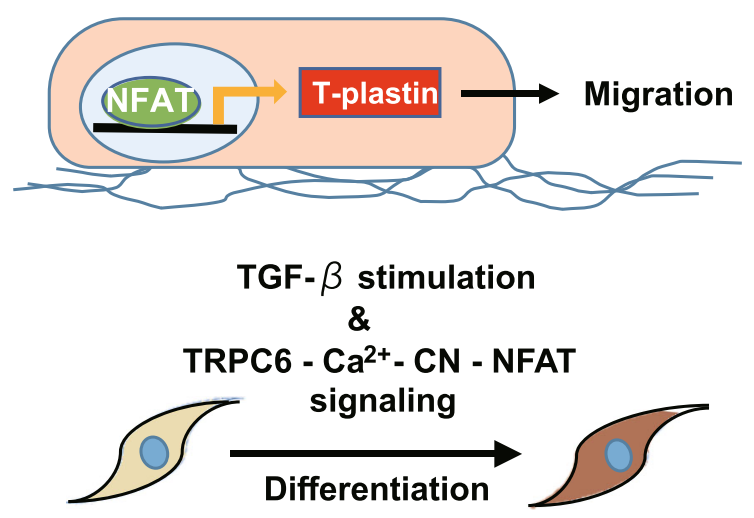

Fibroblast

Myofibroblast

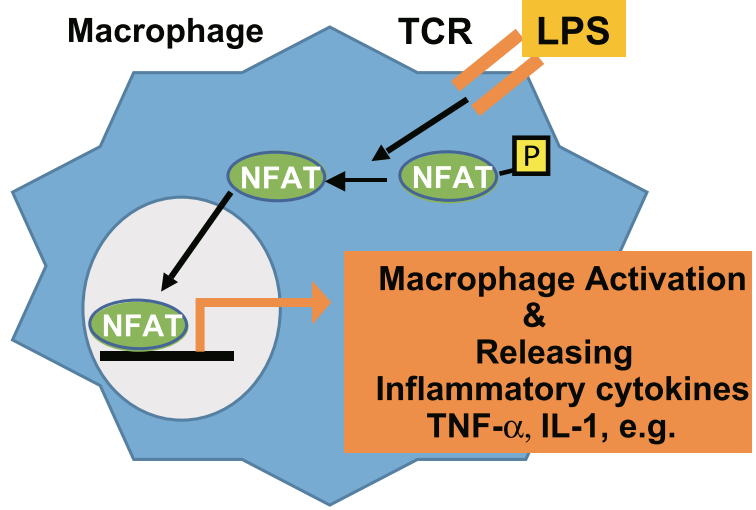

\section{Inflammation}

\section{Angiogenesis}

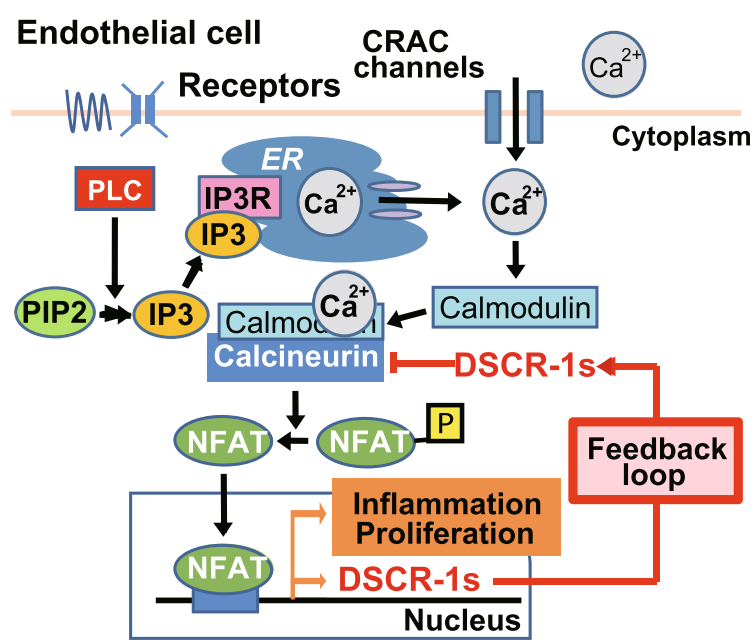

Fig. 1 Schematic illustration of NFAT-mediated wound healing processes. Wound healing steps are summarized following the orders of coagulation, inflammation, and the subsequent re-epithelization, granulation, and angiogenesis. CRAC; calcium release-activated calcium, PLC; phospholipase C, PIP2; phosphatidylinositol 4,5-bisphosphate, IP3; inositol trisphosphate, ER; endoplasmic reticulum

Fibroblasts from calcineurin B knockout mice were reported to indicate "activated phenotypes" with high migration capacity, increased collagen secretion, and remodeling [21]. Moreover, these fibroblasts decreased the response to TGF- $\beta$. Surprisingly, CsA treatment alone failed to change the fibroblast-mediated collagen secretion [22]. The precise mechanism of the differences between CsA and the calcineurin null mutated mice is not well understood, but at least it can be caused via the non-genomic effects under the CsA treatment or the different CsA inhibitory thresholds between the downstream calcineurin-mediated transcription factors, NFAT, and myocyte enhancer factor (MEF)2.
During the granulation process, tissue urgently regenerates in the lack of blood circulation. Thus, hypoxic conditions usually happen, and it is believed that the relieving hypoxia-induced factor (HIF) $1 / 2 \alpha$ induction and the stabilization are critical for the proper wound healings [23]. Shortage of HIF-1 $\alpha$ can be caused to form an intractable ulcer, whereas HIF-1 $\alpha$ overexpression in dermal fibroblasts, in turn, can be led to fibrotic disease such as keloid formation [24]. Moreover, it is reported that hypoxia-mediated activation of NFAT1 occurs through HIF-2 $\alpha$, but it does not occur through HIF-1 $\alpha$. Also, knockdown or chemical inhibition of HIF- $2 \alpha$ inhibited hypoxia-induced NFAT1 nuclear translocation. 
Moreover, overexpression of HIF-2 $\alpha$, not HIF-1 $\alpha$, increased NFAT1 transcriptional activity in pulmonary fibroblasts. There are two possibilities of activating NFAT1 signaling by HIF- $2 \alpha$. One of the possibilities is that HIF- $2 \alpha$ induces the expression of positive components in NFAT signaling or the genes that upregulate NFAT signaling. It has been reported that hypoxia increases NFAT1 expression in HIFs [24], and the activation of HIF- $2 \alpha$ increases mRNA expression levels of NFAT1 and 4 [25]. Another possibility of activating NFAT signaling by HIF- $2 \alpha$ is direct interaction of HIF$2 \alpha$ with NFAT1. Further elucidations such as proteinprotein interaction analysis or reporter assays would be needed to uncover the detailed mechanism of the correlation between hypoxia and NFAT signaling.

Myofibroblast formation is necessary for proper wound healing. TGF- $\beta$ stimulates the differentiation from the original fibroblasts, which caused contraction of wound sites [26]. Myofibroblast has bold microfilament bundles including actin, and it shows not only higher secretion of ECMs, but also contractile features like smooth muscle, which contributes to wound shrinkage [27]. The calcium channel, TRPC6, mediated-NFAT signaling can involve the myofibroblast differentiation process [28]. Deleted TRPC6 delayed wound healing, whereas such the phenotype was rescued by the administration of constitutively active calcineurin. Following these reports, CsA administration leads to a significant decrease in both wound contraction levels and accumulation of hydroxyproline, the marker for reparative collagen deposition [29], suggesting that NFAT signaling not only promoted the inflammation of wounds, but also proceeded to the re-epithelialization and granulation step during the proper healing process. Interestingly, it has been reported that microamperage electrical stimulation (MES) increases NFAT activation, resulting in increased wound healing capacities [30, 31]. MES can increase the granulation and accelerated the reepithelialization process via the increase of dermal collagen production. Electrical stimulation also increased the proliferation of myofibroblasts via the NFAT activation [32]. Collectively, these findings suggest that MES and the resulting NFAT activation can be a new therapeutic way against pathological dermal wounds.

\section{NFAT signaling in angiogenesis}

Cell proliferation under the tissue regeneration process needs enough oxygen and nutrient supplies, so that neovessel formation from existing vessels, angiogenesis, is necessary for wound healing. Angiogenesis is stimulated by many angiocrine factors which are predominantly secreted from inflammatory cells. Thus, inflammation and the following angiogenesis are tightly connected. Exquisite coupling of inflammation and angiogenesis would be critical for adequate healings. In this theory, patients treated with the anti-angiogenesis drug, such as bevacizumab, or diabetes patients appear to have delayed wound healing, mainly due to dysregulation of angiogenesis [33, 34].

We have previously reported both VEGF and thrombin induce NFAT nuclear localization. The following upregulation of various NFAT downstream angiogenesis-related genes involves TF, Early growth response (Egr)2/3, Cox2, bone morphogenic protein (Bmp)2/4, and Cxcr4/7 [35, 36]. Moreover, VEGF but not TNF- $\alpha$ signals preferentially activate NFAT rather than NF- $\mathrm{kB}$. Then, they induce various inflammatoryrelated genes: vascular and intercellular cell adhesion molecule (Vcam and Icam) 1, E-selectin, and monocyte chemotactic protein (Mcp) 1. Not only in in vitro cultured cells, NFAT activations are also indispensable for angiogenesis-related proper development in mice. NFAT2 null mutation indicates embryonic lethality in embryonic days (E)13.5-17.5 due to failure of the artery and coronally endocardium-mediated valve formation [37]. Combined null mutation of NFAT3 and 4 also revealed lethality at E11.5 by the disorganization of growing vessels leading to failure of fully assemble matured vessels [38]. Calcium-calcineurin-responsive NFAT is recognized to NFAT1 to 4 , and all subtypes are expressed in at least primary cultured endothelium from various organs. Thus, it is still needed to verify why such distinct phenotypic differences are observed among each NFAT null mutation in mice. To uncover the mechanisms against the phenotypic differences, several advanced comprehensive approaches, genome-wide chromatin immunoprecipitation (ChIP)-seq by using each specific NFAT antibody to verify the specified downstream targeted genes, and the targeted proteomics to identify the physical protein-protein interaction with each NFAT [39] are available with recent technical proceedings.

NFAT hyperactivation or sustained activation usually occurs for destabilization of cell stability. As an adjusted feedback molecule for NFAT activation in endothelial cells, we have first identified and reported the specific gene, the Down syndrome critical region (Dscr)-1 [35]. Dscr-1 stable expression in the endothelium autoinhibits the NFAT nuclear localization, resulting in attenuated tumor growth, metastasis to the lung, and septic inflammation [40, 41] (Fig. 1). Dscr-1 predominantly encodes two types of isoform. Long isoform (Dscr-1L) contains exon1, 5 to 7 , and short isoform (DSCR-1s) contains exons 4 to 7 (Fig. 2A and B). However, typically in wound healing processes, the functional differences between long and short Dscr-1 isoforms have not yet been studied. To that end, we have succeeded to generate each isoform-specific knockout mouse via TALEN and 


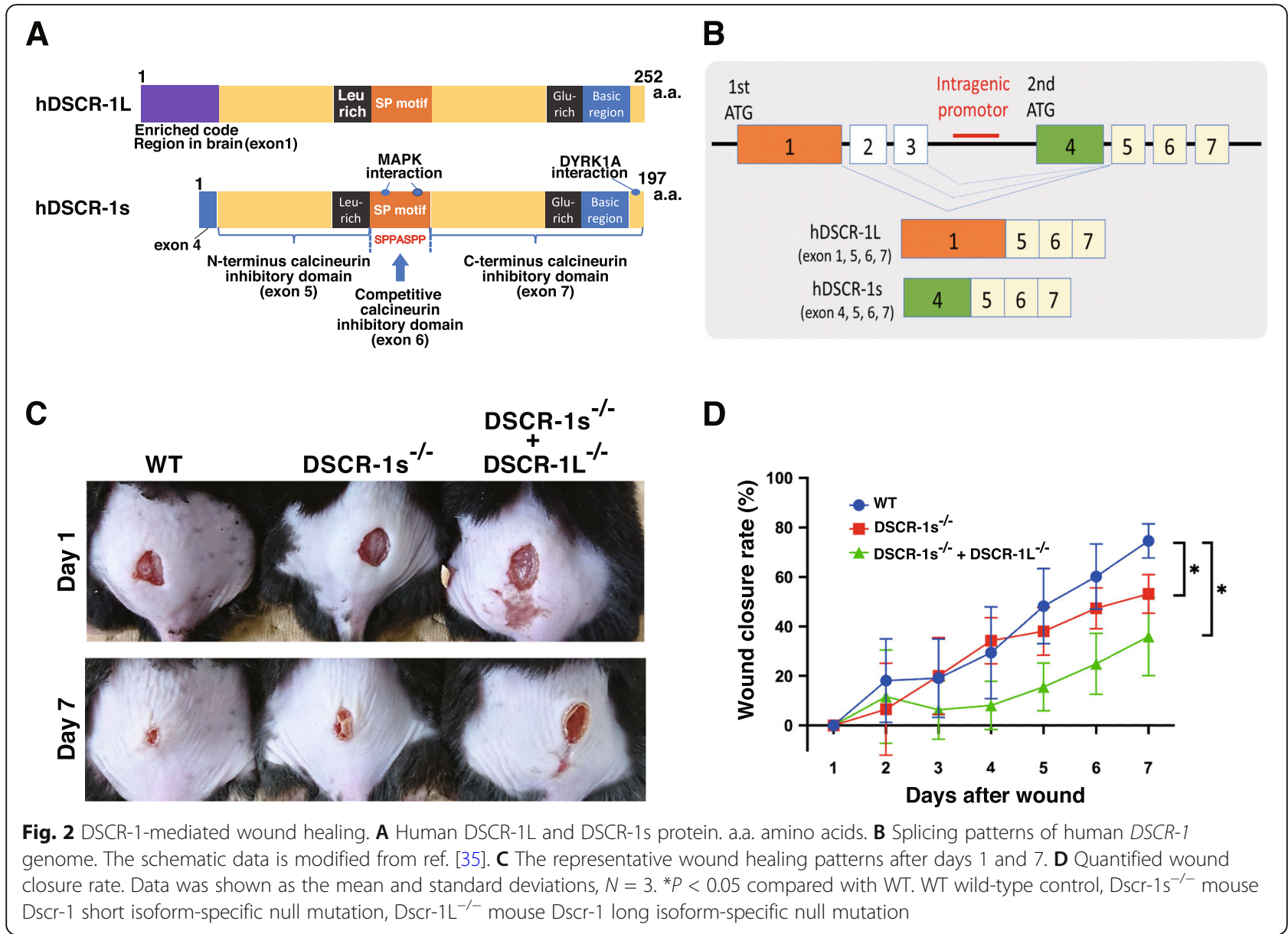

CRISPR/Cas9 technology. As a primal test, we showed a part of data that short isoform null mutation, Dscr- $1 \mathrm{~s}^{-1-}$, delayed wound healing 30\% compared to the wildtype control. In contrast, Dscr-1s and L combined null mutation caused the wound healing delay 60\% than control (Fig. 2C and D). It has been reported that loss of Dscr-1 caused hyperactivation of NFAT. Based on this knowledge, Dscr-1 knockout mice may impair inflammation and the subsequent angiogenesis relay process via hyperactivation of NFAT. Further defined wound healing data with isoform-specific Dscr-1 knockout mice would be available and they will be useful for the discussion of current dermis ointment with CsA, tacrolimus, and sirolimus, an aspect of safety and effectiveness with angiogenesis.

\section{Conclusions}

Spatial and temporal dysregulation or dysfunction of the wound healing process causes various symptoms involving fibrosis, keloid formation, and intractable ulcer that might lead to feeling down due to worsening changes of visual or un-visual aspects of complications in the body. Wound healing processes are involved in multiple steps as discussed above. We realized calcium signaling and the following calcineurin-NFAT activation axis are correlated in all of these healing processes (Fig. 1).

Classically, NFAT-mediated gene upregulations lead to well-known $\mathrm{T}$ cell differentiations and activation, but most recently, many reports also showed the NFAT activity correlates with innate immune cell activation, bone metabolism, angiogenesis, and tissue regenerations [42]. NF- $\kappa \mathrm{B}$, we felt, is the most famous or studied transcription factor for controlling inflammation-mediated cell growth or apoptosis. These critical functions need to feedback control system, such as $I-\kappa B$, to maintain homeostasis [43]. Similarly, our mainly identified DSCR1 indeed works as a feedback modulation for NFAT overactivation. Dscr-1 was initially named as the location of the 21th chromosome, and currently, it was uncovered that it really correlates with Down syndrome patients mediating the strong resistance of the solid tumor burden and the malignancy [44]. Moreover, DSCR-1 stable expression protects the mortality of septic severe inflammations and cytokine storms [40].

During the writing of this review, people in the world suffered from the pandemic of SARS-COV2, COVID-19. 
One of the reasons for the unexpected malignancy of COVID-19 is an immune uncontrolled cytokine storm, lead by the over-secretion of IL-6, TNF- $\alpha$, and IFN $\gamma$, e.g., [45]. These cytokines are known to stimulate immunity and inflammation in our body. Moreover, VEGF secreted from lungs may correlate with the morbidity and mortality of SARS-COV2, as shown in detail in sepsis patients [46]. It has been reported that non-structural protein 1 of SARS-COV2 can be interacted with the immunophilin modulator domain of calcineurin, which induces the IL-2 expression in macrophages [47]. CsA treatment may work in not only the immunosuppression but also the virus replication inhibition [48]. Taken together, it will be a vital candidate for NFAT activation and the accurate control ways, for further drug screenings or future therapy against the SARS-COV2.

\begin{abstract}
Abbreviations
NFAT: Nuclear factor of activated T cell; VEGF: Vascular endothelial growth factor; FGF: Fibroblast growth factor; PDGF: Platelet-derived growth factor; EGF: Epithelial growth factor; CSA: Cyclosporine A; TF: Tissue factor; COX: Cyclooxygenase; IL: Interleukin; TLR: Toll-like receptors; LPS: Lipopolysaccharide; MEF: Myocyte enhancer factor; HIF: Hypoxia-induced factor; MES: Microamperage electrical stimulation; Egr: Early growth response; Bmp: Bone morphogenic protein; Cxcr: Chemokine receptor chemokine (C-XC motif) receptor; TNF-a: Tumor necrosis factor-a; NF-kB: Nuclear factor kappa-light-chain-enhancer of activated B cells; Vcam: Vascular cell adhesion molecule; Icam: Intercellular cell adhesion molecule; Mcp: Monocyte chemotactic protein; ChIP: Chromatin immunoprecipitation; DSCR-1: Down syndrome critical region-1; SARS-COV2: Severe acute respiratory syndrome
\end{abstract} coronavirus 2; COVID-19: Coronavirus disease 2019; IFN: Interferon

\section{Acknowledgements}

Not applicable.

\section{Authors' contributions}

T. Manabe., writing the initial manuscript and the data presentation; H.P., a major contributor in writing the manuscript; and T.M., conceptualization and a major contributor in writing the manuscript. All authors read and approved the final manuscript.

\section{Authors' information}

Manabe, T. is a master degree student studying wound healing related to angiogenesis and inflammation. Park, H. is an undergraduate Biopharmacology student originally from Korea with an especially top score of English skill. Minami, T. is a PI of vascular biology and medical laboratory.

\section{Funding}

This study was supported by a Grant-in-Aid for Scientific Research on Innovative Areas from the Ministry of Education, Culture, Sports, Sciences, and Technology in Japan (to TM).

\section{Availability of data and materials}

The datasets during and/or analyzed during the current study are available from the corresponding author on reasonable request.

\section{Declarations}

\section{Ethics approval and consent to participate}

All animal care and the experimental procedures as shown in Fig. 2 followed the instruction from the committee of Kumamoto University (approval number: 097). All animals were allowed free access to water and diets.

\section{Consent for publication}

Not applicable.

\section{Competing interests}

The authors declare that they have no competing interests.

Received: 19 May 2021 Accepted: 2 August 2021

Published online: 18 August 2021

\section{References}

1. Koh TJ, DiPietro LA. Inflammation and wound healing: the role of the macrophage. Expert Rev Mol Med. 2011;13:e23. https://doi.org/10.1017/S14 62399411001943.

2. Singer AJ, Clark RAF. Cutaneous wound healing. N Engl J Med. 1999;341(10): 738-46. https://doi.org/10.1056/NEJM199909023411006.

3. Eckes B, Zigrino P, Kessler D, Holtkötter O, Shephard P, Mauch C, et al. Fibroblast-matrix interactions in wound healing and fibrosis. Matrix Biol. 2000;19(4):325-32. https://doi.org/10.1016/50945-053X(00)00077-9.

4. Werner S, Krieg T, Smola H. Keratinocyte-fibroblast interactions in wound healing. J Invest Dermatol. 2007;127(5):998-1008. https://doi.org/10.1038/sj. jid.5700786.

5. Broughton G, Janis JE, Attinger CE. Wound healing: an overview. Plast Reconstr Surg. 2006;117(7):1e-S-32e-S. https://doi.org/10.1097/01.prs.0000222 562.60260.f9.

6. Lupulescu A, Habowsky J. Effects of calcitonin on epidermal regeneration and collagen synthesis in rabbits with experimental wounds. Exp Pathol (Jena). 1978;16(1):290-302. https://doi.org/10.1016/S0014-4908(78)80033-7.

7. Ekeland A, Myhre L, Underdal T. Effects of salmon-calcitonin on mechanicalproperties of healing and intact bone and skin in rats. Acta Orthop Scand. 1983;54(3):462-9. https://doi.org/10.3109/17453678308996603.

8. Oda Y, Tu CL, Menendez A, Nguyen T, Bikle DD. Vitamin D and calcium regulation of epidermal wound healing. J Steroid Biochem Mol Biol. 2016; 164:379-85. https://doi.org/10.1016/j.jsbmb.2015.08.011.

9. Gratuze M, Noel A, Julien C, Cisbani G, Milot-Rousseau P, Morin F, et al. Tau hyperphosphorylation and deregulation of calcineurin in mouse models of Huntington's disease. Hum Mol Genet. 2015;24(1):86-99. https://doi.org/10.1 093/hmg/ddu456.

10. Gil MR. Overview of the coagulation system. Transfusion Medicine and Hemostasis: Clinical and Laboratory Aspects. 3rd ed; 2019. p. 559-64.

11. Hernandez GL, Volpert OV, Iniguez MA, Lorenzo E, Martinez-Martinez S, Grau $\mathrm{R}$, et al. Selective inhibition of vascular endothelial growth factor-mediated angiogenesis by cyclosporin $\mathrm{A}$ : roles of the nuclear factor of activated $\mathrm{T}$ cells and cyclooxygenase 2. J Exp Med. 2001;193(5):607-20. https://doi.org/1 0.1084/jem.193.5.607.

12. Bochkov VN, Mechtcheriakova D, Lucerna M, Huber J, Malli R, Graier WF, et al. Oxidized phospholipids stimulate tissue factor expression in human endothelial cells via activation of ERK/EGR-1 and Ca++/NFAT. Blood. 2002; 99(1):199-206. https://doi.org/10.1182/blood.V99.1.199.

13. Hawwari A, Burrows J, Vadas MA, Cockerill PN. The human IL-3 locus is regulated cooperatively by two NFAT-dependent enhancers that have distinct tissue-specific activities. J Immunol (Baltimore, Md : 1950). 2002; 169(4):1876-86.

14. Zanoni I, Granucci F. Regulation and dysregulation of innate immunity by NFAT signaling downstream of pattern recognition receptors (PRRs). Eur J Immunol. 2012;42(8):1924-31. https://doi.org/10.1002/eji.201242580.

15. Weller K, Foitzik K, Paus R, Syska W, Maurer M. Mast cells are required for normal healing of skin wounds in mice. Faseb J. 2006;20(13):2366-+.

16. Raja SK, Garcia MS, Isseroff R. Wound re-epithelialization: modulating keratinocyte migration in wound healing. Front Biosci. 2007;12(8-12):284968. https://doi.org/10.2741/2277.

17. Lin CS, Park T, Chen ZP, Leavitt J. Human plastin genes. Comparative gene structure, chromosome location, and differential expression in normal and neoplastic cells. J Biol Chem. 1993;268(4):2781-92. https://doi.org/10.1016/ S0021-9258(18)53842-4.

18. Brun C, Demeaux A, Guaddachi F, Jean-Louis F, Oddos T, Bagot M, et al. Tplastin expression downstream to the calcineurin/NFAT pathway is involved in keratinocyte migration. PLoS One. 2014;9(9):e104700. https://doi.org/10.13 71/journal.pone.0104700.

19. Moloney FJ, Keane S, O'Kelly P, Conlon PJ, Murphy GM. The impact of skin disease following renal transplantation on quality of life. $\mathrm{Br} J$ Dermatol. 2005;153(3):574-8. https://doi.org/10.1111/j.1365-2133.2005.06699.x.

20. Deodhar AK, Rana RE. Surgical physiology of wound healing: a review. J Postgrad Med. 1997;43(2):52-6. 
21. Lieberman A, Ryeom SW, Pure E. The role of calcineurin/NFAT signaling in fibroblast homeostasis and activation. PlumX Metrics. 2019. https:// repository.upenn.edu/dissertations/AAI22588512/.

22. Esposito C, Fornoni A, Cornacchia F, Bellotti N, Fasoli G, Foschi A, et al. Cyclosporine induces different responses in human epithelial, endothelial and fibroblast cell cultures. Kidney Int. 2000;58(1):123-30. https://doi.org/1 0.1046/j.1523-1755.2000.00147.x.

23. Ruthenborg RJ, Ban JJ, Wazir A, Takeda N, Kim JW. Regulation of wound healing and fibrosis by hypoxia and hypoxia-inducible factor-1. Mol Cells. 2014;37(9):637-43. https://doi.org/10.14348/molcells.2014.0150.

24. Zhang Z, Nie FF, Kang CF, Chen B, Qin ZL, Ma JX, et al. Increased periostin expression affects the proliferation, collagen synthesis, migration and invasion of keloid fibroblasts under hypoxic conditions. Int J Mol Med. 2014; 34(1):253-61. https://doi.org/10.3892/ijmm.2014.1760.

25. Senavirathna LK, Huang CQ, Yang XY, Munteanu MC, Sathiaseelan R, Xu D, et al. Hypoxia induces pulmonary fibroblast proliferation through NFAT signaling. Sci Rep. 2018;8(1):2709. https://doi.org/10.1038/s41598-018-21073$x$.

26. ADaTDH I. Fibroblast differentiation in wound healing and fibrosis. Int Rev Cytol. 2007;257:143-79. https://doi.org/10.1016/S0074-7696(07)57004-X.

27. Hinz B. Myofibroblasts. Exp Eye Res. 2016;142:56-70. https://doi.org/10.1016/ j.exer.2015.07.009.

28. Davis J, Burr AR, Davis GF, Birnbaumer L, Molkentin JD. A TRPC6-dependent pathway for myofibroblast transdifferentiation and wound healing in vivo. Dev Cell. 2012;23(4):705-15. https://doi.org/10.1016/j.devcel.2012.08.017.

29. Nemlander A, Ahonen J, Wiktorowicz K, Vonwillebrand E, Hekali R, Lalla M, et al. Effect of cyclosporine on wound-healing - an analysis with viscous cellulose sponges. Transplantation. 1983;36(1):1-6. https://doi.org/10.1097/ 00007890-198307000-00001.

30. Bayat M, Asgari-Moghadam Z, Maroufl M, Rezaie FS, Rakhshan M. Experimental wound healing using microamperage electrical stimulation in rabbits. J Rehabil Res Dev. 2006;43(2):219-26. https://doi.org/10.1682/JRRD.2 005.05.0089

31. Alvarez OM, Mertz PM, Smerbeck RV, Eaglstein WH. The healing of superficial skin wounds is stimulated by external electrical-current. J Invest Dermatol. 1983;81(2):144-8. https://doi.org/10.1111/1523-1747.ep12543498.

32. Chen QQ, Zhang W, Chen XF, Bao YJ, Wang J, Zhu WZ. Electrical field stimulation induces cardiac fibroblast proliferation through the calcineurinNFAT pathway. Can J Physiol Pharmacol. 2012;90(12):1611-22. https://doi. org/10.1139/y2012-133.

33. Falanga $\vee$. Wound healing and its impairment in the diabetic foot. The Lancet. 2005;366(9498):1736-43. https://doi.org/10.1016/S0140-673 6(05)67700-8.

34. Gordon CR, Rojavin Y, Patel M, Zins JE, Grana G, Kann B, et al. A review on bevacizumab and surgical wound healing: an important warning to all surgeons. Ann Plast Surg. 2009;62(6):707-9. https://doi.org/10.1097/SAP. Ob013e3181828141.

35. Minami T, Horiuchi K, Miura M, Abid MR, Takabe W, Noguchi N, et al. Vascular endothelial growth factor- and thrombin-induced termination factor, Down syndrome critical region-1, attenuates endothelial cell proliferation and angiogenesis. J Biol Chem. 2004;279(48):50537-54. https:// doi.org/10.1074/jbc.M406454200.

36. Minami T, Miura M, Aird WC, Kodama T. Thrombin-induced autoinhibitory factor, Down syndrome critical region-1, attenuates NFAT-dependent vascular cell adhesion molecule-1 expression and inflammation in the endothelium. J Biol Chem. 2006;281(29):20503-20. https://doi.org/10.1074/ jbc.M513112200.

37. de la Pompa JL, Timmerman LA, Takimoto H, Yoshida H, Elia AJ, Samper E, et al. Role of the NF-ATc transcription factor in morphogenesis of cardiac valves and septum. Nature. 1998;392(6672):182-6. https://doi.org/10.103 $8 / 32419$.

38. Graef IA, Chen F, Chen L, Kuo A, Crabtree GR. Signals transduced by Ca2+/ calcineurin and NFATc3/C4 pattern the developing vasculature. Cell. 2001; 105(7):863-75. https://doi.org/10.1016/S0092-8674(01)00396-8.

39. J-i S, Kanki Y, Makihara C, Schadler K, Miura M, Manabe Y, et al. Genomewide approaches reveal functional vascular endothelial growth factor (VEGF)-inducible nuclear factor of activated T cells (NFAT) c1 binding to angiogenesis-related genes in the endothelium. J Biol Chem. 2014;289(42): 29044-59.

40. Minami T, Yano K, Miura M, Kobayashi M, Suehiro J, Reid PC, et al. The Down syndrome critical region gene 1 short variant promoters direct vascular bed-specific gene expression during inflammation in mice. J Clin Invest. 2009:119(8):2257-70. https://doi.org/10.1172/JCl35738.

41. Minami T, Jiang S, Schadler $K$, Suehiro J, Osawa T, Oike $Y$, et al. The calcineurin-NFAT-angiopoietin-2 signaling axis in lung endothelium is critical for the establishment of lung metastases. Cell Rep. 2013;4(4):709-23. https://doi.org/10.1016/j.celrep.2013.07.021.

42. Minami T. Calcineurin-NFAT activation and DSCR-1 auto-inhibitory loop: how is homoeostasis regulated? J Biochem. 2014;155(4):217-26. https://doi. org/10.1093/jb/mvu006.

43. Hoffmann A, Levchenko A, Scott ML, Baltimore D. The IkappaB-NF-kappaB signaling module: temporal control and selective gene activation. Science. 2002;298(5596):1241-5. https://doi.org/10.1126/science.1071914.

44. Baek KH, Zaslavsky A, Lynch RC, Britt C, Okada Y, Siarey RJ, et al. Down's syndrome suppression of tumour growth and the role of the calcineurin inhibitor DSCR1. Nature. 2009;459(7250):1126-30. https://doi.org/10.1038/na ture08062.

45. Hojyo S, Uchida M, Tanaka K, Hasebe R, Tanaka Y, Murakami M, et al. How COVID-19 induces cytokine storm with high mortality. Inflamm Regen. 2020 40(1):37. https://doi.org/10.1186/s41232-020-00146-3.

46. Yano K, Okada Y, Beldi G, Shih SC, Bodyak N, Okada H, et al. Elevated levels of placental growth factor represent an adaptive host response in sepsis. J Exp Med. 2008:205(11):2623-31. https://doi.org/10.1084/jem.20080398.

47. Min YQ, Mo Q, Wang J, Deng F, Wang H, Ning YJ. SARS-CoV-2 nsp1: bioinformatics, potential structural and functional features, and implications for drug/vaccine designs. Front Microbiol. 2020;11:587317. https://doi.org/1 0.3389/fmicb.2020.587317.

48. Sauerhering L, Kupke A, Meier L, Dietzel E, Hoppe J, Gruber AD, et al. Cyclophilin inhibitors restrict Middle East respiratory syndrome coronavirus via interferon-lambda in vitro and in mice. Eur Respir J. 2020:56(5):1901826. https://doi.org/10.1183/13993003.01826-2019.

\section{Publisher's Note}

Springer Nature remains neutral with regard to jurisdictional claims in published maps and institutional affiliations.
Ready to submit your research? Choose BMC and benefit from:

- fast, convenient online submission

- thorough peer review by experienced researchers in your field

- rapid publication on acceptance

- support for research data, including large and complex data types

- gold Open Access which fosters wider collaboration and increased citations

- maximum visibility for your research: over $100 \mathrm{M}$ website views per year

At $\mathrm{BMC}$, research is always in progress.

Learn more biomedcentral.com/submissions 